\title{
Ocorrência de doenças oftalmológicas em eqüinos utilizados para tração urbana na cidade de Londrina, PR
}

\author{
Occurrence of ophthalmologic diseases in horses used for urban cart hauling in \\ Londrina, PR, Brazil
}

\section{Peter Reichmann ${ }^{* I}$ Antônio Cezar de Oliveira Dearo ${ }^{\mathrm{I}}$ Tais Casonato Rodrigues ${ }^{\mathrm{II}}$}

\section{RESUMO}

Com o objetivo de verificar a ocorrência de doenças oculares em eqüinos utilizados para serviços de tração urbana na cidade de Londrina, $P R$, foram revistos os registros clínicos de 805 eqüinos atendidos no Hospital Veterinário da Universidade Estadual de Londrina no período entre 1992 e 2007. Nesses registros clínicos foram verificados 25 casos de doenças oftalmológicas (3,1\%), compostas por 12 casos (48\%) de doenças da córnea, seis casos (24\%) de catarata, seis casos (24\%) de doenças da conjuntiva (paralelas a outras enfermidades oculares ou não), dois casos (8\%) de uveíte recorrente eqüina, um caso de carcinoma de células escamosas da terceira pálpebra, um caso de lesão crônica de pálpebra, com necrose e perda do globo ocular, e um caso de Phthisis bulbi (4\% cada). A principal causa das enfermidades oftalmológicas diagnosticadas nesses animais foi traumática (36\% dos casos). A maioria das doenças diagnosticadas neste estudo, se não tratadas adequadamente, pode resultar em cegueira e, conseqüentemente, pode inutilizar o animal para uso em tração urbana. Isso reforça a necessidade de conscientização dos carroceiros sobre a importância e a profilaxia dessas enfermidades.

Palavras-chave: oftalmologia, doenças de eqüinos, doenças oftalmológicas.

\section{ABSTRACT}

The clinical records of 805 horses admitted to the Veterinary Hospital of the State University of Londrina between 1992 and 2007 were reviewed in order to establish the occurrence of ophthalmologic diseases in horses used for hauling carts in Londrina, Paraná, Brazil. Among these records, there were 25 ophthalmologic cases (3.1\%), composed of 12 cases (48\%) of corneal diseases, six cases (24\%) of cataracts, six cases (24\%) of conjunctival diseases (associated or not to other lesions), two cases (8\%) of recurrent equine uveitis, one case of squamous cell carcinoma of the third eyelid, one case of chronic necrotic eyelid lesion with loss of the eye globe and one case of phthisis bulbi (4\% each). Trauma was the most important etiology for eye diseases diagnosed in this study (36\%). Most of the ophthalmologic diseases seen in this study may cause blindness if not adequately treated, and this might prevent the animal from performing draught activities. Therefore, this study helps to emphasize the need of continuously making cart owners aware of the importance and prevention of such conditions.

Key words: ophthalmology, diseases of horses, ophthalmologic diseases.

\section{INTRODUÇÃO}

As doenças oftalmológicas têm diversas etiologias e podem comprometer em maior ou menor grau a visão dos eqüinos. Essas doenças podem afetar todas as estruturas do olho ou cada uma delas de maneira individualizada. $\mathrm{O}$ tratamento e a recuperação do paciente dependem do agente etiológico, da estrutura ocular envolvida e da gravidade e da cronicidade do caso. A importância das enfermidades oftalmológicas reside no fato de que dependendo do grau de comprometimento da visão o animal pode vir a ser inutilizado para o trabalho a que se propõe (LAVACH, 1990).

A ocorrência de enfermidades oftalmológicas na clínica veterinária de eqüinos varia de $3 \%$ a $27 \%$ (SOMMER, 1984; SZEMES \& GERHARDS, 2000). Entre essas enfermidades, as mais freqüentemente diagnosticadas são as doenças da úvea, com prevalência de até aproximadamente 50\%, e

'Departamento de Clínicas Veterinárias, Universidade Estadual de Londrina (UEL), Centro de Ciências Agrárias (CCA), Campus Universitário, CP 6001, 86051-990, Londrina, PR, Brasil. E-mail: reichman@uel.br. *Autor para correspondência.

"Curso de Medicina Veterinária, UEL, Londrina, PR, Brasil 
as doenças da córnea, com prevalência de até $28 \%$. As doenças palpebrais, da conjuntiva e/ou da esclera, do sistema lacrimal, do humor vítreo e da lente são menos freqüentes na espécie eqüina (SOMMER, 1984; SPIESS, 1997). Uma das doenças de maior freqüência em populações de eqüinos é a uveíte recorrente eqüina (URE), com prevalência de $8 \%$ a 25\% nos Estados Unidos (GILGER at al., 2001). A ocorrência dessa enfermidade em levantamentos de casuística clínica varia de $1,4 \%$ a quase 50\% (SOMMER, 1984; DWYER et al., 1995; SPIESS, 1997; SZEMES \& GERHARDS, 2000).

Portanto, o objetivo deste trabalho foi verificar a ocorrência de doenças oftalmológicas em eqüinos utilizados para tração urbana no município de Londrina, PR, e atendidos no Hospital Veterinário (HV) da Universidade Estadual de Londrina (UEL), a fim de fornecer dados epidemiológicos e compará-los aos relatados na literatura internacional.

\section{MATERIAL E MÉTODOS}

Foram revistos os registros clínicos de 805 eqüinos destinados à tração urbana em Londrina, PR, atendidos no HV-UEL no período entre 1992 e 2007. Esses eqüinos eram todos mestiços e tinham idades que variavam de um mês a 17 anos (média de 5,7 anos). Destes, 443 eram fêmeas e 362 eram machos (119 inteiros e 236 castrados). Em relação à pelagem, 249 eram castanhos, 241 eram alazões, 132 eram tordilhos, 83 eram baios, 69 eram pampas, 16 eram pretos e 15 eram brancos. Todos os eqüinos foram submetidos a exame clínico geral e, de acordo com os resultados desses exames, foram realizados os exames específicos necessários e houve posterior encaminhamento desses animais de acordo com cada caso (MAREK \& MÓCSY, 1965; TAYLOR \& HILLYER, 1997; SPIERS, 1999). Os exames oftalmológicos foram realizados conforme preconizado na literatura (LAVACH, 1990; CRISPIN, 2004a). Quando necessário, os eqüinos foram sedados e/ou anestesiados localmente para a realização do exame.

\section{RESULTADOS}

De um total de 805 eqüinos utilizados para tração urbana atendidos no HV-UEL entre 1992 e 2007, 25 eqüinos (3,1\%) apresentaram doenças oftalmológicas (Tabela 1). Em dois casos de úlcera de córnea, havia descemetocele. Dos seis casos de catarata, três eram bilaterais e três eram unilaterais, perfazendo um total de nove olhos afetados, nos quais em quatro a catarata foi diagnosticada como madura e em cinco como imatura. Um dos casos de ceratoconjuntivite foi associado à dacriocistite. Um caso de conjuntivite era de origem parasitária, causada por um quadro de habronemose cutânea envolvendo o ângulo medial do olho. Dos casos de URE, um era unilateral e o outro bilateral. O eqüino com lesão unilateral apresentava título sorológico de 1:100 para Leptospira interrogans sorovares cynopteri e icterohaemorrhagiae e o eqüino com lesão bilateral, título de 1:800 para o sorovar pomona. A laceração de pálpebra com perda do globo ocular era uma lesão crônica com miíase e necrose local. Cinco casos de úlcera de córnea, dois casos de ceratoconjuntivite e os casos de ceratite e laceração da pálpebra tinham origem traumática. A partir dos dados clínicos não foi possível estabelecer a etiologia das lesões nos demais casos.

\section{DISCUSSÃO}

O número reduzido de casos não possibilitou o estabelecimento de uma relação entre uma maior ou

Tabela 1 - Doenças oftalmológicas em 25 eqüinos utilizados para tração urbana na cidade de Londrina, PR, no período de 1992 a 2007.

\begin{tabular}{lllc}
\hline Doenças oftalmológicas & $\mathrm{n}$ & $\%$ & $\mathrm{OD}^{\mathrm{a} / \mathrm{OE}^{\mathrm{b}} / \mathrm{B}^{\mathrm{c}}}$ \\
\hline Úlcera de córnea & 7 & 28 & $4 / 3 /-$ \\
Catarata & 6 & 24 & $1 / 2 / 3$ \\
Ceratoconjuntivite & 4 & 16 & $2 / 1 / 1$ \\
Conjuntivite & 2 & 8 & $1 / 1 /-$ \\
Uveite recorrente eqüina & 2 & 8 & $-/ 1 /-$ \\
Carcinoma de células escamosas da terceira pálpebra & 1 & 4 & $-/ 1 /-$ \\
Ceratite & 1 & 4 & $1 /-/-$ \\
Laceração da pálpebra com perda do globo ocular & 1 & 4 & $1 /-/-$ \\
Phthisis bulbi & 1 & 4 & $11 / 9 / 5$ \\
Total & 25 & 100 & \\
\hline
\end{tabular}

${ }^{a}$ casos em que apenas o olho direito foi afetado; ${ }^{b}$ casos em que apenas olho esquerdo foi afetado; ${ }^{\mathrm{c}}$ casos em que ambos os olhos foram afetados.

Ciência Rural, v.38, n.9, dez, 2008. 
menor ocorrência de determinada enfermidade oftalmológica com sexo, idade ou cor dos animais. Apesar de a ocorrência de doenças oftalmológicas neste trabalho $(3,1 \%)$ ser praticamente igual $(3 \%)$ à relatada em outro levantamento semelhante (SOMMER, 1984), é provável que esse valor não corresponda à realidade dessas doenças na população geral de eqüinos aqui estudada. Valores de 7,4\% e 27,5\% foram relatados por outros autores (SZEMES \& GERHARDS, 2000; HURN \& TURNER, 2006). Tais valores foram verificados em estudos populacionais de doenças oftalmológicas em eqüinos e devem estar mais próximos da realidade, inclusive da nossa, pois estudos populacionais independem da percepção do problema por parte do proprietário e de sua disponibilidade em procurar atendimento. A baixa percepção da importância desse tipo de enfermidade pelos carroceiros pode ser exemplificada por um dos casos de URE descrito neste trabalho, em que o eqüino, apesar de apresentar a forma clássica da doença em um quadro agudo, foi encaminhado ao HV-UEL com queixa de claudicação, sem que o proprietário notasse o problema oftalmológico. A grande freqüência de compra e venda ou troca de eqüinos entre os carroceiros também dificulta o esclarecimento da história clínica pregressa e prejudica o estabelecimento de um diagnóstico mais específico, como ocorreu no caso de phthisis bulbi, em que o eqüino fora adquirido há três ou quatro meses, com o quadro já estabelecido e sem mais informações sobre a evolução clínica.

As úlceras de córnea foram as doenças mais prevalentes neste estudo, corroborando dados de outros trabalhos (BROOKS, 2002). Como as lesões de córnea são consideradas o principal motivo de consulta inicial na oftalmologia eqüina (MATTHEWS, 2004), acredita-se que esse realmente seja um problema comum na região, já que, por motivos financeiros, o HV-UEL se tornou praticamente a única opção de atendimento médico veterinário de animais de tração na região abrangida por este estudo.

A URE é considerada a principal causa de cegueira em eqüinos e estima-se que afete de $1,4 \%$ a 25\% de populações de eqüinos (SILLERUD, 1987; SCHWINK, 1992; DWYER et al., 1995; SZEMES \& GERHARDS, 2000). A ocorrência da URE neste trabalho foi de quatro a seis vezes menor que a relatada em estudos semelhantes (SOMMER, 1984; MCLAUGHLIN et al., 1992). Seria de se esperar uma ocorrência maior de URE na população estudada se considerada a proporção de eqüinos soropositivos para leptospirose e a forte associação dessa enfermidade com a URE (LAVACH, 1990; BRANDES et al., 2007), mais especificamente com os sorovares pomona nos Estados Unidos (SILLERUD et al., 1987; DWYER et al., 1995) e gryppothyphosa na Europa (BREM et al., 1999; HARTSKEERL et al., 2004). Em um levantamento sorológico em eqüinos utilizados para tração urbana na região de Londrina, PR, aproximadamente $67 \%$ dos animais apresentaram sorologia positiva para L interrogans. Destes, 13,1\% eram positivos para o sorovar gryppothyphosa e 6,6\% para o sorovar pomona (HASHIMOTO et al., 2007). Possíveis variações regionais em relação à importância da leptospirose como etiologia da URE (GILGER et al., 2008) podem existir e talvez possam explicar o baixo número de casos de URE neste trabalho. Além disso, apesar de a leptospirose ser considerada a principal causa de URE, vários outros agentes etiológicos e situações epidemiológicas podem estar envolvidos em casos dessa doença (MATTHEWS \& HANDSCOMBE, 1983; LAVACH, 1990).

A alta ocorrência de catarata neste trabalho (24\%) destaca-se, contrariando dados da literatura, em que essa doença teve prevalência de 1,6\% em um levantamento de casuística (SOMMER, 1984) e de 1,5\% em um estudo populacional (HURN \& TURNER, 2006). Em nenhum dos casos aqui relatados a catarata foi a queixa primária do proprietário e sim um "achado de exame clínico”. A etiologia da catarata é bastante variada, porém essa doença é freqüentemente associada à uveíte ou ao traumatismo envolvendo o globo ocular (MATTHEWS, 2000; BROOKS, 2005; FIFE et al., 2006). Neste trabalho não se conseguiu informações de anamnese nem foram observados sinais clínicos ao exame oftalmológico que pudessem associar algum dos casos de catarata a uma causa específica.

O carcinoma de células escamosas foi o único neoplasma verificado neste levantamento e corresponde ao tumor mais freqüentemente observado na terceira pálpebra de eqüinos (CRISPIN, 2004b) e do olho(BROOKS, 2002).

Uma parte considerável dos casos (36\%) teve origem comprovadamente traumática, revelando incidência de falhas no manejo desses eqüinos. Isso reforça a necessidade de orientações aos carroceiros quanto à importância dessas enfermidades e de um correto tratamento e profilaxia dos eqüinos afetados.

\section{CONCLUSÃO}

As enfermidades oftalmológicas na clínica de eqüinos utilizados para tração urbana na cidade de Londrina, PR, afetam mais freqüentemente a córnea, a lente e, em menor freqüência, a úvea. A principal causa para as enfermidades oftalmológicas nesses animais é de origem traumática. A maioria das doenças 
diagnosticadas, se não tratadas a tempo e adequadamente, pode resultar em cegueira e, portanto, podem inutilizar o animal para uso em tração urbana, 0 que reforça a necessidade da conscientização dos carroceiros sobre a importância da profilaxia e do tratamento adequado dessas doenças.

\section{REFERÊNCIAS}

BRANDES, K. et al. Recurrent uveitis in horses: vitreal examinations with ultrastructural detection of leptospires. Journal of Veterinary Medicine A, v.54, p.270-275, 2007.

BREM, S. et al. 35 Leptospirenisolationen aus Glaskörpern von 32 Pferden mit rezidivierender Uveitis (ERU). Berliner und Münchner Tieräztliche Wochenschrift, v.112, n.1011, p.390-393, 1999.

BROOKS, D.E. Equine ophthalmology. Proceedings AAEP, v.48, p.300-313, 2002.

BROOKS, D.E. Phacoemulsification cataract surgery in the horse. Clinical Techniques in Equine Practice, v.4, n.1, p.11-20, 2005.

CRISPIN, S.M. Examination of the eye and adnexa. In: BARNETT, K.C et al. Equine ophthalmology. 2. ed, Philadelphia: Saunders., 2004a. p.1-13.

CRISPIN, S.M. Third eyelid and caruncle. In: BARNETT, K.C et al. Equine ophthalmology. 2.ed. Philadelphia: Saunders, 2004b. p.73-82,

DWYER, A.E. et al. Association of leptospiral seroreactivity and breed with uveitis and blindness in horses: 372 cases (19861993). Journal of the American Veterinary Medical Association, v.207, n.10, p.1327-1331, 1995.

FIFE, T.M. et al. Clinical features and outcomes of phacoemulsification in 39 horses: A retrospective study (19932003). Veterinary Ophthalmology, v.9, n.5, p.361-368, 2006.

GILGER, B.C. et al. Use of an intravitreal sustained-release cyclosporine delivery device for treatment of equine recurrent uveitis. American Journal of Veterinary Research, v.62, n.12, p.1892-1896, 2001.

GILGER, B.C. et al. Role of bacteria in the pathogenesis of recurrent equine uveitis in horses from Southeastern United States. American Journal of Veterinary Research, (aceito para publicação em fevereiro 2008).

HARTSKEERL, R.A. et al. Classification of Leptospira from eyes of horses suffering from recurrent equine uveitis. Journal of Veterinary Medicine B, v.51, p.110-115, 2004.
HASHIMOTO, V.Y. et al. Occurrence of antibodies against Leptospira ssp. in horses of the urban area of Londrina, Paraná, Brazil. Revista do Instituto de Medicina Tropical de São Paulo, v.49, n.5, p.327-330, 2007.

HURN, S.D.; TURNER, A.G. Ophthalmic examination findings in Thoroughbred racehorses in Australia. Veterinary Ophthalmology, v.9, n.2, p.95-100, 2006.

LAVACH, J.D. Large animal ophthalmology. St Louis: Mosby, 1990. 395 p.

MAREK, J.; MÓCSY, J. Tratado de diagnóstico clínico de las enfermidades internas de los animales domésticos. Barcelona: Labor, 1965. 676 p.

MATTHEWS, A.G. Lens opacities in the horse: a clinical classification. Veterinary Ophthalmology, v.3, n.2-3, p.6571,2000

MATTHEWS, A.G. Cornea. In: BARNETT, K.C. et al. Equine ophthalmology. 2. ed. Philadelphia: Saunders, 2004. p.107147 .

MATTHEWS, A.G.; HANDSCOMBE, M.C. Uveitis in the horse: a review of the aetiological and immunopathological aspects of the disease. Equine Veterinary Journal, Suppl., v.2, p.61-64, 1983.

MCLAUGHLIN, S.A. et al. Diagnosis and treatment of lens diseases. Veterinary Clinics of North America Equine Practice, v.8, n.3, p.575-585, 1992.

SCHWINK, K.L. Equine uveitis. Veterinary Clinics of North America Equine Practice, v.8, n.3, p.557-574, 1992.

SILLERUD, C.L. et al. Serologic correlation of suspected Leptospira interrogans serovar pomona-induced uveitis in a group of horses. Journal of the American Veterinary Medical Association, v.191, n.12, p.1576-1578, 1987.

SOMMER, U. Vorkommen und Behandlung von Augenkrankheiten beim Pferd. 1984. 100f. Tese (Doutorado em Medicina Veterinária) - Pós-graduação em Medicina Veterinária, Tierärztliche Hochschule Hannover.

SPEIRS, V.C. Exame clínico de eqüinos. Porto Alegre: Artes Médicas Sul, 1999. 366p.

SPIESS, B.M. Zur equinen rezidivierenden Uveitis. Schweizer Archiv für Tierheilkunde, v.139, n.3, p.126-133, 1997.

SZEMES, P.A; GERHARDS, H. Untersuchungen zur Prävalenz der equinen rezidivierenden Uveitis im Großraum Köln - Bonn. Praktischer Tierarzt, v.81, n.5, p.408-420, 2000.

TAYLOR, F.G.R.; HILLYER, M.H. Diagnostic techniques in equine medicine. Philadelphia: Saunders 1997. 348p. 